\title{
PRODUÇÃO E CARACTERIZAÇÃO DE MICROPARTÍCULAS DE POLI(ÁCIDO LÁTICO-CO-ÁCIDO GLICÓlICO) (PLGA) E CLORIDRATO DE METFORMINA
}

\author{
G. R. MEDEIROS ${ }^{1}$, T. C. dos $\operatorname{SANTOS}^{2}$, M. A. BATTISTI ${ }^{2}$, A. M. CAMPOS ${ }^{2}$, S. R. S. \\ FERREIRA $^{1}$, B. A. M. CARCIOFI ${ }^{1}$ \\ ${ }^{1}$ Universidade Federal de Santa Catarina, Departamento de Engenharia Química e Engenharia de \\ Alimentos \\ ${ }^{2}$ Universidade Federal de Santa Catarina, Departamento de Ciências Farmacêuticas \\ E-mail para contato: glauciarmd@gmail.com
}

\begin{abstract}
RESUMO - O uso do cloridrato de metformina (CM) como um agente terapêutico para o tratamento do diabetes tipo 2 é frequentemente associado com a incidência de efeitos colaterais gastrointestinais. Para reduzir estes efeitos, uma alternativa seria a liberação sustentada deste fármaco, que pode ser alcançada através da aplicação do CM em um sistema de liberação controlada constituído por polímeros biodegradáveis. Micropartículas de poli(ácido lático-co-ácido glicólico) (PLGA) foram preparadas pela técnica da dupla emulsão com extração/evaporação do solvente usando o CM como composto ativo modelo de natureza hidrofílica. O diâmetro médio das micropartículas foi 243,50 $\mu \mathrm{m}$. As micropartículas foram altamente porosas e apresentaram baixos valores para a eficiência de encapsulamento $(1,4 \pm 0,1 \%)$ e percentual real de encapsulamento $(0,33 \pm 0,02 \%)$. As micropartículas apresentaram formato esférico, estrutura matricial porosa, diâmetro médio de 243,50 $\mu \mathrm{m}$ e distribuição de tamanho uniforme. Os resultados indicam a dificuldade relacionada à formação de micropartículas de PLGA e compostos hidrofílicos de baixa massa molecular pela técnica da dupla emulsão.
\end{abstract}

\section{INTRODUÇÃO}

Os poliésteres estão entre a classe de polímeros biodegradáveis mais usada e estudada, dentre eles destacam-se o poli(ácido lático) (PLA), o poli(ácido glicólico) (PGA) e seus copolímeros, como o poli(ácido lático-co-ácido glicólico) (PLGA). As razões para o amplo uso do PLGA estão relacionadas à sua biodegradabilidade, biocompatibilidade e sua aprovação para uso clínico em humanos por autoridades de regulamentação (Siepmann e Siepmann, 2006; Fredenberg et al., 2011). O PLGA é degradado in vivo em seus monômeros, o ácido lático e o ácido glicólico, os quais são subprodutos biocompatíveis e toxicologicamente seguros, sendo posteriormente eliminados do corpo humano por vias metabólicas normais (Jain, 2000). Outras razões para o uso do PLGA estão relacionadas à sua disponibilidade comercial e boa solubilidade em diversos solventes orgânicos (Lewis, 1990; Wischke e Schwendeman, 2008).

A técnica da extração/evaporação do solvente é comumente usada para incorporar ou encapsular 


\section{9 a 22 de outubro de 2014 \\ Florianópolis/SC}

compostos ativos em micropartículas de PLGA (Geze et al., 1999), por ser um processo simples que não requer o uso de equipamentos complexos, além de ser rápida, dependendo apenas da taxa na qual o solvente é removido (Cohen et al., 1995). Dependendo da natureza do composto ativo a ser encapsulado, a técnica da dupla emulsão água-óleo-água (a/o/a) com extração/evaporação do solvente é mais adequada, por ser indicada para o encapsulamento de compostos hidrossolúveis ou hidrofílicos, enquanto que a técnica da emulsão simples (o/a) é recomendada para compostos de natureza hidrofóbica (Jain, 2000).

O diabetes é uma das maiores causas de mortes no mundo e está frequentemente associada com o estilo de vida sedentário e a obesidade (Jain e Gupta, 2009). O cloridrato de metformina (CM) é um agente oral hipoglicêmico usado no tratamento do diabetes mellitus não dependente de insulina (diabetes tipo 2) (Cheng et al., 2004). Embora o CM seja um fármaco importante para as políticas de saúde pública, particularmente no Brasil (Block et al., 2008), a sua terapia está frequentemente associada com efeitos colaterais gastrointestinais, tais como desconforto gástrico, náusea e diarreia (Balan et al., 2001). Desta forma, uma alternativa viável para reduzir estes efeitos colaterais é a incorporação do CM em micropartículas de PLGA, permitindo uma taxa de liberação sustentada e constante do composto ativo, principalmente em formulações projetadas para a liberação pela via oral, uma vez que a absorção do CM ocorre na parte inicial do intestino (Colo et al., 2002).

Desta maneira, o objetivo deste trabalho foi avaliar a viabilidade da incorporação do CM, como composto ativo modelo de natureza hidrofílica, em micropartículas de PLGA utilizando a técnica da dupla emulsão com extração/evaporação do solvente. Além disso, o estudo envolveu a caracterização morfológica das micropartículas formadas.

\section{MATERIAIS E MÉTODOS}

\subsection{Materiais}

Os seguintes materiais foram usados conforme recebidos. PLGA com razão molar de lactídeo e glicolídeo de 50:50 (Resomer ${ }^{\circledR}$ RG 503H) foi fornecido pela Evonik Degussa Brasil Ltda (São Paulo, Brasil). CM foi obtido da empresa Aarti Drugs Ltd (Mumbai, Índia). Álcool polivinílico (PVA) (Mowiol $^{\circledR}$ 40-88) foi adquirido da Sigma-Aldrich Brasil Ltda (São Paulo, Brasil). Diclorometano (pureza 99,5\%) foi fornecido pela Cromoline Química Fina Ltda (São Paulo, Brasil).

\subsection{Preparo das micropartículas}

As micropartículas de PLGA e CM foram preparadas usando a técnica da dupla emulsão $\left(\mathrm{a}_{1} / \mathrm{o} / \mathrm{a}_{2}\right)$ com extração/evaporação do solvente, como descrito por (Lamprecht et al., 2004). Brevemente, $150 \mathrm{mg}$ de CM foram dissolvidas em $500 \mu \mathrm{L}$ de água destilada (fase aquosa interna, $\mathrm{a}_{1}$ ) e $500 \mathrm{mg}$ de PLGA foram dissolvidos em $5 \mathrm{~mL}$ de diclorometano (fase oleosa, o). Após a adição da $\mathrm{a}_{1}$ na fase oleosa, a emulsificação foi realizada usando um Ultra-Turrax ${ }^{\circledR}$ (modelo T25-basic, IKAWerke GmbH and Co., Staufen, Alemanha) por 2 minutos a $17500 \mathrm{rpm}$. Esta primeira emulsão $\left(\mathrm{a}_{1} / \mathrm{o}\right)$ foi dispersa em $75 \mathrm{~mL}$ de uma solução aquosa de PVA 0,5\% (m/m) (fase aquosa externa, $\left.a_{2}\right)$ e a emulsificação foi realizada durante 5 minutos a $900 \mathrm{rpm}$ com agitação magnética com o objetivo de 
formar a dupla emulsão $\left(a_{1} / o / a_{2}\right)$. Esta emulsão resultante foi mantida sob agitação constante em um agitador magnético com banho termostático (modelo DI-06, Dist Ltda, Florianópolis, Brasil) por aproximadamente uma hora a $800 \mathrm{rpm}$ e $40{ }^{\circ} \mathrm{C}$ após a adição de $100 \mathrm{~mL}$ de solução aquosa de PVA $0,1 \%(\mathrm{~m} / \mathrm{m})$, com o objetivo de permitir a completa extração/evaporação do solvente e a solidificação das micropartículas. As micropartículas sólidas foram coletadas por centrifugação (centrífuga modelo 4K15, Sigma GmbH, Osterode, Alemanha) por 5 minutos a 4500 rpm e lavadas três vezes com água destilada para remover o PVA residual e o CM não incorporado. Posteriormente, as micropartículas foram liofilizadas (liofilizador modelo LD 1500, Terroni, São Carlos, Brasil) por 24 horas e armazenadas em dessecador à temperatura ambiente até a realização das análises. $\mathrm{O}$ rendimento do processo foi calculado com base na massa de micropartículas liofilizadas em relação à soma inicial das massas de PLGA e CM usadas no processo.

\subsection{Determinação do percentual real de encapsulamento}

A quantidade CM incorporada nas micropartículas de PLGA foi determinada através da dissolução de $20 \mathrm{mg}$ de micropartículas em $1 \mathrm{~mL}$ de diclorometano. Após a completa dissolução do polímero em banho ultrassônico (modelo USC 700, Unique Ltda, Indaiatuba, Brasil), 5 mL de água destilada foram adicionados e a solução resultante foi agitada em vortex para induzir a precipitação do PLGA. A solução foi centrifugada por 5 minutos a $2500 \mathrm{rpm}$ e a concentração de CM na fase aquosa foi determinada usando espectrofotômetro de UV-visível (modelo UV-1800, Shimadzu, Kyoto, Japão) no comprimento de onda de $232 \mathrm{~nm}$. A curva de calibração do CM foi linear na faixa de concentração de 2,5 a $10 \mu \mathrm{g} / \mathrm{mL}$ com um coeficiente de determinação $\left(R^{2}\right)$ igual a 0,999 . Todos os experimentos foram realizados em triplicata e os resultados expressam a média de três experimentos independentes. A eficiência de encapsulamento (EE) (Equação 1) e o percentual real de encapsulamento (PRE) (Equação 2) foram calculados como descrito por Priamo et al. (2010):

$$
\begin{aligned}
& E E(\%)=\frac{\text { massa de composto ativo nas micropartículas }}{\text { massa de composto ativo usado na formulação }} \times 100 \\
& P R E(\%)=\frac{\text { massa de composto ativo nas micropartículas }}{\text { massa de micropartículas }} \times 100
\end{aligned}
$$

\subsection{Tamanho e distribuição de tamanho da micropartícula}

O tamanho e a distribuição do tamanho das micropartículas de PLGA e CM foram obtidas por difração a laser usando um Mastersizer 2000 (Malvern Instruments Ltd, Malvern, Reino Unido). Para a análise, as micropartículas foram dispersas em água destilada e os resultados foram expressos como o diâmetro médio baseado no volume $\left(d_{4,3}\right)$. Além disso, a distribuição do tamanho $(D T)$ das micropartículas foi expressa pelos diâmetros de volume equivalente a $10 \%\left(d_{0,1}\right), 50 \%\left(d_{0,5}\right)$ e $90 \%$ $\left(d_{0,9}\right)$ do volume cumulativo (Mirhosseini e Amid, 2012), de acordo com a Equação 3: 


\section{9 a 22 de outubro de 2014 \\ Florianópolis/SC}

$$
D T=\frac{d_{0,9}-d_{0,1}}{d_{0,5}}
$$

\subsection{Morfologia das micropartículas}

A morfologia e as características internas e externas das micropartículas foram analisadas em microscópio eletrônico de varredura (MEV) (modelo JSM-6390LV, Jeol, Tokyo, Japão) com uma voltagem de aceleração de $10 \mathrm{kV}$. Com o objetivo de visualizar a superfície externa, as micropartículas foram colocadas em um porta-amostras usando uma fita adesiva de carbono e, posteriormente, recobertas com uma fina camada de ouro sob vácuo. As seções transversais das micropartículas também foram obtidas com o objetivo de visualizar a estrutura interna. Primeiramente, as micropartículas foram incluídas em um meio para congelamento (Jung Tissue Freezing Medium, Leica Instruments $\mathrm{GmbH}$, Nussloch, Alemanha) e congeladas por 2 horas a $-20{ }^{\circ} \mathrm{C}$. Um criostato equipado com um micrótomo (modelo CM1850 UV, Leica Instruments GmbH, Nussloch, Alemanha) foi usado para cortar finas seções do bloco congelado contendo as micropartículas $-20{ }^{\circ} \mathrm{C}$ (Wong et al., 2001). As seções transversais obtidas foram colocadas na fita adesiva do porta-amostras metálico, secas e recobertas com ouro para a realização da análise.

\section{RESULTADOS E DISCUSSÃO}

A escolha de uma técnica de formulação de partículas adequada depende, basicamente, das propriedades físicas do composto ativo a ser encapsulado (Cohen-Sela et al., 2009). As principais vantagens da técnica da dupla emulsão são a simplicidade e uma estreita distribuição de tamanho das micropartículas resultantes. No entanto, uma desvantagem é a possibilidade de baixos valores de $E E$, uma vez que compostos hidrofílicos possuem uma tendência natural para difundirem das gotículas da emulsão primária para a fase aquosa externa durante a etapa de remoção do solvente (Takeuchi et al., 2001). As micropartículas de PLGA e CM foram obtidas aplicando a técnica da dupla emulsão com extração/evaporação do solvente. Os resultados para o rendimento, a eficiência de encapsulamento e o percentual real de encapsulamento das micropartículas preparadas sem otimização dos parâmetros de formulação estão apresentados na Tabela 1.

Tabela 1 - Eficiência de encapsulamento, percentual real de encapsulamento, rendimento do processo, tamanho da partícula e distribuição de tamanho das micropartículas de PLGA e CM.

$\begin{array}{lcccc}E E(\%) & P R E(\%) & \text { Rendimento }(\%) & d_{4,3}(\mu \mathrm{m}) & D T \\ 1,4 \pm 0,1 & 0,33 \pm 0,02 & 71 \pm 2 & 243,50 & 1,02\end{array}$

Baixos valores de $E E$ e $P R E$ podem ser atribuídos às perdas de composto ativo que ocorreram durante as etapas da formação da dupla emulsificação e da evaporação/extração do solvente. Este tipo de perda é potencializada devido à alta solubilidade aquosa do composto ativo, podendo ser causada pela difusão do $C M$ da primeira emulsão $\left(a_{1} / o\right)$ para a fase aquosa externa $\left(a_{2}\right)$ enquanto a fase polimérica encontra-se em um estado semissólido. 
Considerando que a rota de administração determina o tamanho das micropartículas e levando em conta a viabilidade do uso das micropartículas de PLGA e CM para o tratamento do diabetes tipo 2 , o diâmetro obtido $\left(d_{4,3}\right.$, Tabela 1$)$, associado com uma estreita distribuição de tamanho, designado pelo valor de $D T$ (Tabela 1) próximo a um, indicam a adequação das micropartículas para a administração pela via oral.

As micropartículas de PLGA e CM apresentaram formato esférico com superfície e estrutura interna altamente porosa, como mostrado na Figura 1. Ainda, a ausência de núcleos ocos nas seções transversais das micropartículas pode estar relacionada à presença do agente emulsificante PVA, que evitou a coalescência das gotículas da emulsão. Além disso, a ausência de cristais de CM depositados na superfície da micropartícula indica uma distribuição homogênea do composto ativo.

(a)

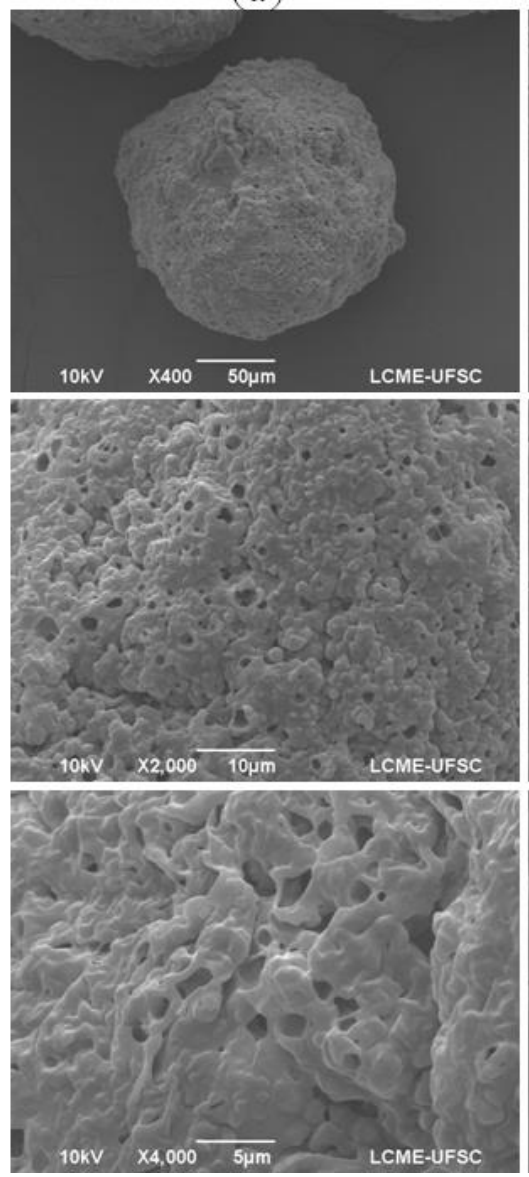

(b)
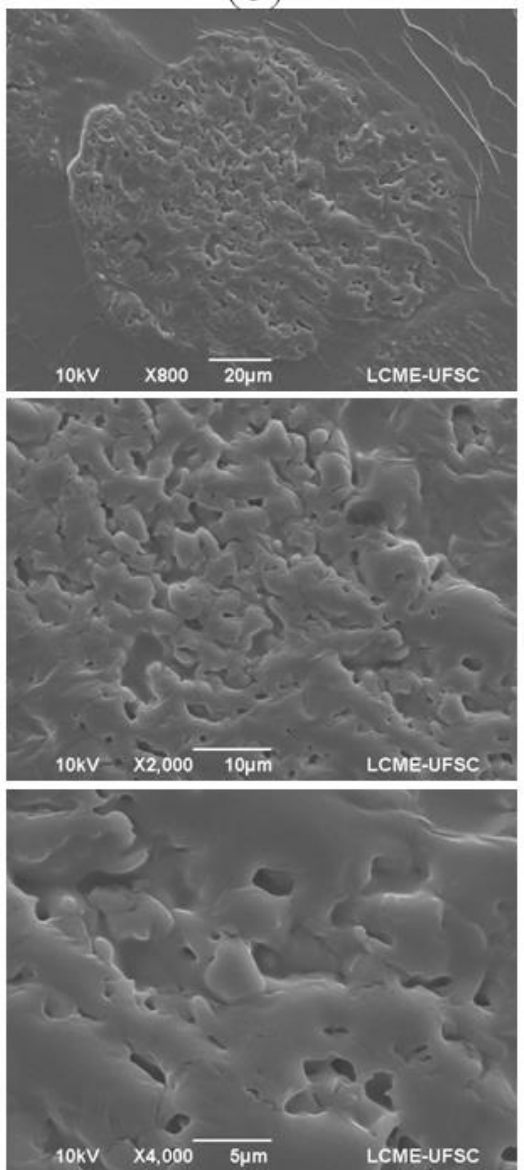

Figura 1 - Imagens obtidas por MEV da morfologia externa (a) e interna (b) de micropartículas de PLGA e CM em diferentes escalas de ampliação.

A alta porosidade das micropartículas produzidas pela técnica da dupla emulsão pode ser controlada pelo volume e a estabilidade da fase aquosa interna (Crotts e Park, 1995). Por exemplo, a presença de um composto hidrofílico na emulsão primária gera um gradiente de concentração e um influxo de água da fase aquosa externa $\left(\mathrm{a}_{2}\right)$, produzindo canais que conectam as regiões internas da 

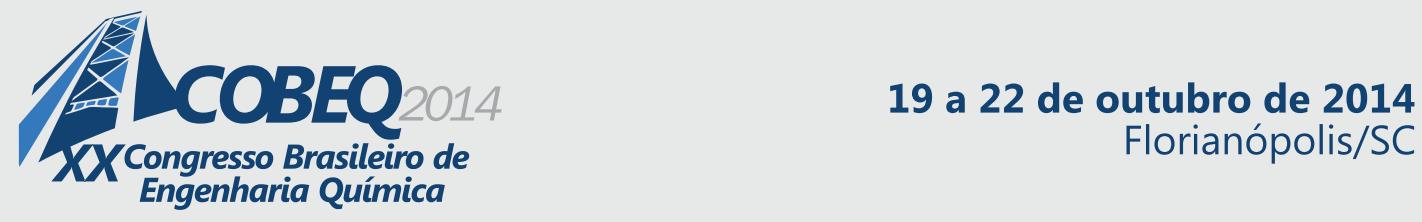

partícula com a sua superfície (Allison, 2008). Como resultado, o volume da fase aquosa interna aumenta. Este volume maior aumenta a resistência à quebra mecânica das gotículas da emulsão durante a etapa de agitação (Crotts e Park, 1995). Como as micropartículas são liofilizadas para remover a água e promover a forma de pó, este maior volume da fase aquosa interna resultará em poros maiores, como consequência da redução do conteúdo de água (Yang et al., 2000).

Neste estudo, o valor de $E E$ foi baixo não apenas pela característica hidrofílica do CM, cuja solubilidade aquosa é maior do que $300 \mathrm{mg} / \mathrm{mL}$ a $25{ }^{\circ} \mathrm{C}$ (Barot et al., 2010), mas também pela baixa massa molecular do composto ativo, igual a 165,62 $\mathrm{g} / \mathrm{mol}$ (Brasil, 2010). A literatura relata que compostos ativos hidrofílicos de baixa massa molecular, tais como o CM, são facilmente transportados através dos poros da micropartícula preenchidos por água, ocasionando baixos valores de EE (Tewes et al., 2007; Fredenberg et al., 2011). Considerando que as micropartículas de PLGA e $\mathrm{CM}$ foram extremamente porosas, a alta solubilidade aquosa aliada à baixa massa molecular do CM podem ser explicações plausíveis para a baixa EE obtida. Segundo Perez et al. (2001), uma consequência da baixa $E E$ é o baixo valor de $P R E$, como também observado neste estudo. Contudo, o baixo valor de PRE pode indicar que o composto ativo está molecularmente disperso em toda a micropartícula polimérica (Klose et al., 2011), sem a formação de agregados ou deposição de cristais de composto ativo na superfície da partícula. Adicionalmente, um estudo envolvendo o encapsulamento do $\mathrm{CM}$ em micropartículas de poli(3-hidroxibutirato-co-3-hidroxivalerato) (PHBV) utilizando a técnica da dupla emulsão também resultou em baixos valores de EE (Farago et al., 2008), demonstrando a dificuldade relacionada à incorporação de compostos ativos hidrofílicos de baixa massa molecular em micropartículas poliméricas usando esta técnica.

\section{CONCLUSÕES}

As micropartículas de PLGA e CM preparadas pela técnica da dupla emulsão com extração/evaporação do solvente apresentam tamanho na faixa micrométrica, além do formato esférico e estruturas interna e externa porosas. Devido às características de alta solubilidade aquosa e baixa massa molecular do CM, a possível difusão do composto ativo das gotículas de emulsão primária para a fase aquosa externa durante a etapa de solidificação da micropartícula, associado à alta porosidade das partículas formadas, promovem baixos valores para a eficiência de encapsulamento e para o percentual real de encapsulamento. Este estudo aborda o potencial de incorporação do CM em micropartículas de PLGA para o tratamento do diabetes tipo 2. Contudo, é importante conduzir mais estudos com o objetivo de otimizar a formulação.

\section{REFERÊNCIAS}

ALLISON, S. D. Effect of structural relaxation on the preparation and drug release behavior of poly(lactic-co-glycolic)acid microparticle drug delivery systems. J. Pharm. Sci., v. 97, p. 20222035, 2008.

BALAN, G.; TIMMINS, P.; GREENE, D. S.; MARATHE, P. H. In vitro-In vivo Correlation (IVIVC) models for metformin after administration of modified-release (MR) oral dosage forms to healthy human volunteers. J. Pharm. Sci., v. 90, p. 1176-1185, 2001.

BAROT, B. S.; PAREJIYA, P. B.; PATEL, T. M.; PARIKH, R. K.; GOHEL, M. C. Development of 


\section{9 a 22 de outubro de 2014 \\ Florianópolis/SC}

directly compressible metformin hydrochloride by the spray-drying technique. Acta Pharm., v. 60, p. 165-175, 2010.

BLOCK, L. C.; SCHEMling, L. O.; COUTO, A. G.; MOURÃO, S. C.; BRESOLIN, T. M. B. Pharmaceutical equivalence of metformin tablets with various binders. Rev. Ciênc. Farm. Básica Apl., 29, p. 29-35, 2008.

BRASIL. Farmacopeia Brasileira, volume 2. Agência Nacional de Vigilância Sanitária. Brasília: Anvisa, 2010.

CHENG, X. X.; CHEN, C.-M.; JAN, S.; CHOU, J. Methods for treating diabets via administration of controlled release metformin. United States. Patent 6790459B1, 2004.

COHEN, S.; CHEN, L. M.; APTE, R. N. Controlled-release of peptides and proteins from biodegradable polyester microspheres - an approach for treating infectious-diseases and malignancies. React. Polym., v. 25, p. 177-187, 1995.

COHEN-SELA, E.; CHORNY, M.; KOROUKHOV, N.; DANENBERG, H. D.; GOLOMB, G. A new double emulsion solvent diffusion technique for encapsulating hydrophilic molecules in PLGA nanoparticles. J. Control. Release, v. 133, p. 90-95, 2009.

COLO, G. D.; FALCHI, S.; ZAMBITO, Y. In vitro evaluation of a system for $\mathrm{pH}$-controlled peroral delivery of metformin. J. Control. Release, v. 80, p. 119-128, 2002.

CROTTS, G.; PARK, T. G. Preparation of porous and nonporous biodegradable polymeric hollow microspheres. J. Control. Release, v. 35, p. 91-105, 1995.

FARAGO, P. V.; RAFFIN, R. P.; POHLMANN, A. R.; GUTERRES, S. S.; ZAWADZKI, S. F. Physicochemical characterization of a hydrophilic model drug-loaded PHBV microparticles obtained by the double emulsion/solvent evaporation technique. J. Braz. Chem. Soc., v. 19, p. 1298-1305, 2008.

FREDENBERG, S.; WAHLGREN, M.; RESLOW, M.; AXELSSON, A. The mechanisms of drug release in poly(lactic-co-glycolic acid)-based drug delivery systems: a review. Int. J. Pharm., v. 415, p. 34-52, 2011.

GEZE, A.; VENIER-JULIENNE, M. C.; MATHIEU, D.; FILMON, R; PHAN-TAN-LUU, R.; BENOIT, J. P. Development of 5-iodo-2'-deoxyuridine milling process to reduce initial burst release from PLGA microparticles. Int. J. Pharm., v. 178, p. 257-268, 1999.

JAIN, R. A. The manufacturing techniques of various drug loaded biodegradable poly(lactide-coglycolide) (PLGA) devices. Biomater., v. 21, p. 2475-2490, 2000.

JAIN, S. K.; GUPTA, A. Development of gelucire 43/01 beads of metformin hydrochloride for floating delivery. AAPS PharmSciTech, v. 10, p. 1128-1136, 2009.

KLOSE, D.; DELPLACE, C.; SIEPMANN, J. Unintended potential impact of perfect sink conditions on PLGA degradation in microparticles. Int. J. Pharm., v. 404, p. 75-82, 2011.

LAMPRECHT, A.; YAMAMOTO, H.; TAKEUCHI, H.; KAWASHIMA, Y. PH-sensitive microsphere delivery increases oral bioavailability of calcitonin. J. Control. Release, v. 98, p. 19, 2004.

LEWIS, D. H. Controlled release of bioactive agents from lactide/glycolide polymers. In: CHASIN, M.; LANGER, R (Ed.). Biodegradable polymers as drug delivery systems: drugs and the pharmaceutical sciences. New York: Marcel Dekker, Inc., v. 45, 1990.

MIRHOSSEINI, H.; AMID, B. T. Influence of chemical extraction conditions on the physicochemical and functional properties of polysaccharide gum from durian (Durio zibethinus) seed. Molecules, v. 17, p. 6465-6480, 2012. 
PEREZ, C.; SANCHEZ, A.; PUTNAM, D.; TING, D.; LANGER, R.; ALONSO, M. J. Poly(lactic acid)-poly(ethylene glycol) nanoparticles as new carriers for the delivery of plasmid DNA. $J$. Control. Release, v. 75, p. 211-224, 2001.

PRIAMO, W. L.; CEZARO, A. M.; FERREIRA, S. R. S.; OLIVEIRA, J. V. Precipitation and encapsulation of $\beta$-carotene in PHBV using carbon dioxide as anti-solvent. J. Supercrit. Fluids, v. 54, p. 103-109, 2010.

SIEPMANN, J.; SIEPMANN, F. Microparticles used as drug delivery systems. Smart Colloid. Mater., v. 133, p. 15-21, 2006.

TAKEUCHI, H.; YAMAMOTO, H.; KAWASHIMA, Y. Mucoadhesive nanoparticulate systems for peptide drug delivery. Adv. Drug Delivery Rev., v. 47, p. 39-54, 2001.

TEWES, F.; MUNNIER, E.; ANTOON, B.; OKASSA, L. N.; COHEN-JONATHAN, S.; MARCHAIS, H.; DOUZIECH-EYROLLES, L.; SOUCÉ, M.; DUBOIS, P.; CHOURPA, I. Comparative study of doxorubicin-loaded poly(lactide-co-glycolide) nanoparticles prepared by single and double emulsion methods. Eur. J. Pharm. Biopharm., v. 66, p. 488-492, 2007.

VIANA, M.; JOUANNIN, P.; PONTIER, C.; CHULIA, D. About pycnometric density measurements. Talanta, v. 57, p. 583-593, 2002.

WISCHKE, C.; SCHWENDEMAN, S. P. Principles of encapsulating hydrophobic drugs in PLA/PLGA microparticles. Int. J. Pharm., v. 364, p. 298-327, 2008.

WONG, H. M.; WANG, J. J.; WANG, C. H. In vitro sustained release of human immunoglobulin G from biodegradable microspheres. Ind. Eng. Chem. Res., v. 40, p. 933-948, 2001.

YANG, Y. Y.; CHIA, H. H.; CHUNG, T. S. Effect of preparation temperature on the characteristics and release profiles of PLGA microspheres containing protein fabricated by double-emulsion solvent extraction/evaporation method. J. Control. Release, v. 69, p. 81-96, 2000. 